\title{
AS TUTELAS PROVISÓRIAS PREVISTAS NO NCPC
}

\author{
Tiago Conde Teixeira
}

\section{INTRODUÇÃO}

É notória a crise da morosidade atualmente enfrentada pelo judiciário, que tem causado um enorme problema para o cidadão que procura dele uma resposta. Muitas foram as tentativas de solucionar o problema, mas, até o momento, não tivemos nenhum benefício concreto. Uma das possíveis soluções era inserir a tutela antecipada para o núcleo dos "procedimentos comuns" e, com isso, eliminar as inúmeras discussões acadêmicas sobre os efeitos das tutelas provisórias, previstas no art. 273 do Código de Processo Civil de 1973 (CPC/73).

A Lei n. 13.105 (Novo Código de Processo Civil - NCPC), de 16 de março de 2015, reformulou significativamente o sistema de tutela judicial baseado em cognição sumária. Com a nova legislação, unifica-se em um único regime geral, sob o nome de "tutela provisória", as tutelas antecipada e cautelar, que se submetiam a disciplinas formalmente distintas no CPC/73. Pelo novo dispositivo processual, as tutelas provisórias se subdividem em tutelas de urgência e de evidência, tratadas em um mesmo título.

Os avanços do NCPC perpassam diversos princípios processuais fundamentais como a celeridade processual, a efetividade da prestação jurisdicional, a ampla defesa e o contraditório, além da segurança jurídica e do devido processo legal. Nesse sentido, importantes instrumentos processuais trouxeram avanços consideráveis ao processo civil, como as tutelas provisórias. 
A inovação corresponde a uma maior aproximação entre os instrumentos de tutela provisória, fato bastante relevante ao direito tributário, como se analisará a seguir. Tanto a tutela de urgência quanto a de evidência buscam, em uma última análise, entregar uma resposta jurisdicional do Estado perante as lides apresentadas ao poder judiciário, prezando sempre pela celeridade processual e pelo devido trâmite legal. As disposições atuais sobre o processo civil trouxeram a possibilidade de interposição das tutelas provisórias de forma antecedente, retirando a vinculação do instrumento provisório com o processo principal e ampliando a admissibilidade de tais mecanismos.

A tutela cautelar no NCPC, por exemplo, sofreu substancial alteração com a extinção da ação cautelar autônoma, mecanismo processual que, já há algum tempo, vinha sendo pouco utilizado. O direito a uma tutela cautelar, entretanto, não foi suprimido com a entrada em vigor do NCPC, mas se resumiu, basicamente, à tutela de urgência cautelar requerida em caráter incidental.

De forma geral, as tutelas provisórias representam juízo não exauriente do processo e possuem a característica principal da reversibilidade de seus efeitos. O juízo exaurido nesses processos tem como base a alta probabilidade de existência do direito e se baseia ora no perigo da demora, ora na evidência do direito pleiteado.

O processo tributário aplica os ditames do direito processual civil de maneira subsidiária, sendo útil a utilização das tutelas provisórias. Na prática, em muitas situações, observa-se o ajuizamento de ações buscando, por exemplo, a concessão de um juízo antecipado às execuções fiscais ou mesmo, por parte da autoridade fiscal, a interposição de ações cautelares que visem assegurar a efetividade de tais ações.

As discussões tributárias que podem ser objeto de tutelas provisórias perpassam tanto matérias meritórias, como se os tributos em análise são ou não devidos, quanto matérias procedimentais, como a apresentação de garantias ou a obtenção de Certidões Positivas com Efeitos Negativos (CPEN). Evidentemente, a depender da natureza da discussão, o contribuinte lançará mão da tutela de urgência ou de evidência, cada qual com peculiaridades a seguir analisadas.

Em um primeiro momento, será analisado o conceito de tutela provisória e suas subdivisões para, então, apresentar um panorama geral da aplicação das tutelas de urgência e evidência especificamente em matéria de direito tributário.

\section{AS TUTELAS PROVISÓRIAS SEGUNDO O NCPC}

No NCPC, o legislador não dedicou um processo autônomo para as tutelas provisórias, possibilitando que sejam concedidas de maneira incidental ou 
antecedente, tanto nos procedimentos comuns quanto nos diferenciados. A tutela provisória deixou de dar lugar a um processo autônomo, sendo que o NCPC buscou aplicar o princípio de interinidade e unicidade do processo mantendo a possibilidade de aplicação incidental das tutelas, conforme dispõe o art. 294, J único. ${ }^{1}$

A tutela provisória é um juízo não exauriente, no qual não se esgotam por completo todas as discussões probatórias e de julgamento, mas apenas se tem um juízo sumário e de probabilidade com relação ao direito requerido. Quaisquer que sejam os mecanismos de antecipação de tutela, deve haver o pressuposto da probabilidade do direito, uma convicção judicial formada a partir de uma cognição sumária das alegações das partes.

A classificação das tutelas provisórias, prevista nos art. 294 e 311 do NCPC, podem ser assim resumidas:

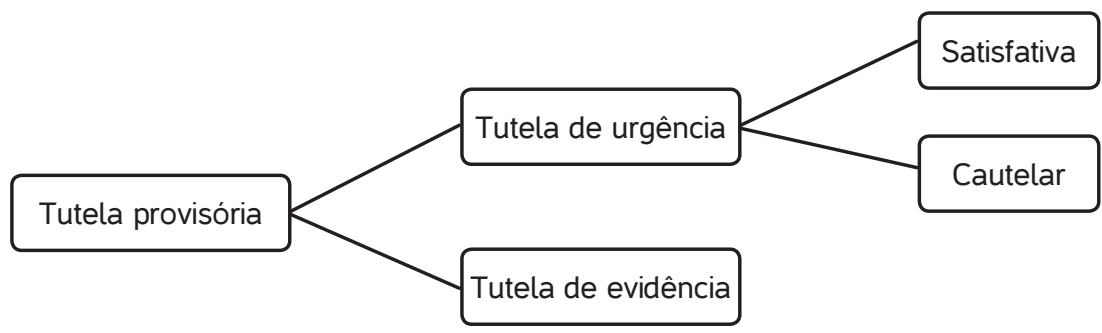

Figura 1 - Classificação das tutelas provisórias segundo o NCPC

Logo, é clara a intenção do legislador de simplificar o instituto das tutelas provisórias.

Em linhas gerais, a tutela provisória poderá ser de urgência ou evidência. A tutela de urgência será concedida quando forem demonstrados elementos que indiquem de forma clara a probabilidade do direito e o perigo na demora da prestação da tutela jurisdicional. Já a tutela de evidência dispensa a demonstração de periculum in mora quando: (i) for claro o abuso do direito de defesa ou o manifesto propósito protelatório da parte; (ii) as alegações de fato puderem ser comprovadas apenas mediante prova documental e houver tese firmada em demandas repetitivas ou em súmula vinculante; (iii) se tratar de pedido reipersecutório fundado em prova documental adequada do contrato de depósito; ou (iv) a petição inicial for

1 "Art. 294. A tutela provisória pode fundamentar-se em urgência ou evidência. Parágrafo único. A tutela provisória de urgência, cautelar ou antecipada, pode ser concedida em caráter antecedente ou incidental." 
instruída com prova documental suficiente dos fatos constitutivos do direito do autor, a que o réu não oponha prova capaz de gerar dúvida razoável.

Dentro das tutelas de urgência, temos duas possibilidades. Nas tutelas satisfativas, é necessário demonstrar para o magistrado, além da urgência, que o direito material estará em risco se não concedida a medida. Já nas cautelares é preciso demonstrar, além da emergência, que a efetividade de um futuro processo estará em risco se a medida não for obtida de imediato. Além de analisar os requisitos propriamente ditos para concessão da tutela provisória, o juiz deverá observar o contexto em que está inserido o pedido formulado pelo autor, observando: (i) o valor do bem jurídico ameaçado; (ii) a dificuldade do autor para provar sua alegação; (iii) a credibilidade da alegação; e (iv) a própria urgência alegada pelo autor.

Tanto no CPC/73 quanto no NCPC, exigem-se para ações de tutela de urgência os requisitos da probabilidade do direito (fumus boni iuris) e do perigo na demora (periculum in mora). No caso das tutelas de evidência, como já explicitado, o pedido deve ser baseado na certeza do direito postulado em juízo. Logo, a tutela de urgência pode ser satisfativa ou cautelar e serve para combater o perigo de dano ou o risco ao resultado útil do processo (art. 300, NCPC). ${ }^{2}$

Luiz Guilherme Marinoni ${ }^{3}$ afirma que esse instrumento é útil para combater um "perigo de ilícito". A primeira das subdivisões dessa espécie, a tutela antecipada ou satisfativa, antecipa o julgamento parcial ou total de mérito, se relacionando com o direito das partes e com o próprio bem da vida. Segundo o autor, há quatro modalidades de tutela satisfativa: (i) tutela inibitória (preventiva contra ocorrência, continuação ou repetição de um ilícito); (ii) tutela repressiva contra o ilícito (para remover os efeitos concretos do ato ilícito); (iii) tutela ressarcitória (na forma específica ou pelo valor equivalente ao do dano); e (iv) tutela do adimplemento (na forma específica ou pelo valor equivalente ao da prestação).

Quando se pede tutela inibitória, objetiva-se evitar a violação de um direito, sendo necessário que se prove o fato que constitua indício de que a violação futura provavelmente ocorrerá. Quando o autor requerer tutela provisória repressiva, ele não se preocupa em evitar um ilícito, mas só em remover os seus efeitos, reparando o dano causado ou promovendo seu ressarcimento, devendo o juiz se ater

2 "Art. 300. A tutela de urgência será concedida quando houver elementos que evidenciem a probabilidade do direito e o perigo de dano ou o risco ao resultado útil do processo."

3 MARINONI, Luiz Guilherme. Novo curso de processo civil. São Paulo: Revista dos Tribunais, 2015. v. 2. 
ao fato violador e à necessidade de a tutela ser prestada rapidamente para que o dano não se agrave.

Ainda com relação à tutela de urgência antecipada, como já exposto, é possível que se pleiteie tal mecanismo de forma antecedente, antes mesmo da formação do processo. Exatamente no ponto que diz respeito ao caráter antecedente da tutela antecipada, o NCPC apresentou importantes mudanças com relação ao dispositivo revogado. Se houver o requerimento de tutela antecipada antecedente e o pedido for concedido, o autor tem a obrigação de aditar petição inicial complementando o processo, sob pena de ter o processo extinto sem resolução do mérito. É importante ressaltar também a possibilidade de estabilização da tutela antecipada, fato que ocorre quando não há recurso do réu impugnando à decisão que concedeu a tutela antecipada. Quando tal juízo se torna estável, ocorre a extinção do processo e a conservação de seus efeitos, sem, contudo, instituir o trânsito em julgamento material.

Há casos em que, para que seja possível a realização de tutela satisfativa do direito, pode ser necessário utilizar-se da tutela cautelar, que visa assegurar que a tutela satisfativa possa futuramente e eventualmente ocorrer. A tutela cautelar relaciona-se com o processo e com os ritos procedimentais que podem existir, funcionando como forma de instrumentalizar o processo e permitindo que não se perca a possibilidade de produzir uma prova, por exemplo.

Situação típica de tutela de urgência cautelar está nas situações em que uma das testemunhas arroladas corre risco de vida, razão pela qual se peticiona tutela cautelar para que ela possa ser ouvida rapidamente sob o risco de prejudicar o desenvolvimento do julgamento do processo no futuro. Em resumo, pode ser entendida como uma espécie de tutela que acautela o processo para que futuramente as outras tutelas - provisórias ou definitivas - possam ocorrer.

No que tange à tutela de evidência, a doutrina processual considera que ela é sempre satisfativa. De acordo com o art. 311 do NCPC, ${ }^{4}$ essa modalidade de tutela poderá ser concedida sem ser preciso demonstrar o perigo de dano ou de risco ao

4 "Art. 311. A tutela da evidência será concedida, independentemente da demonstração de perigo de dano ou de risco ao resultado útil do processo, quando: I - ficar caracterizado o abuso do direito de defesa ou o manifesto propósito protelatório da parte; II - as alegações de fato puderem ser comprovadas apenas documentalmente e houver tese firmada em julgamento de casos repetitivos ou em súmula vinculante; III - se tratar de pedido reipersecutório fundado em prova documental adequada do contrato de depósito, caso em que será decretada a ordem de entrega do objeto custodiado, sob cominação de multa; e IV - a petição inicial for instruída com prova 
resultado útil do processo. A tutela pode ser antecipada em razão de uma defesa inconsistente do réu ou uma enorme probabilidade de que o seja em virtude da indiscutível razão do autor. Há, ainda, o requisito da desnecessidade de dilação probatória, amparada pelo inciso II do mesmo artigo, determinando que as alegações de fato sejam possíveis de se comprovar apenas documentalmente e que haja tese firmada em recursos repetitivos ou súmulas vinculantes.

Em suma, nas tutelas de evidência o autor precisar demonstrar para o magistrado que, independentemente da urgência, o direito é tão cristalino e evidente que o caminho do processo poderá ser "simplificado". Tal situação é de extrema importância para a matéria tributária, visto a carga de elaboração de súmulas e processos amantados de repercussão geral que tramitam nas cortes superiores e no Supremo Tribunal Federal (STF). Assim, é possível que um contribuinte suspenda a exigibilidade do crédito tributário, lançado em sede de tutela de evidência, alegando recursos repetitivos ou julgamentos exarados na suprema corte.

O inciso IV do mesmo art. 311 exige que a petição inicial tenha sido instruída com provas documentais suficientes a respeito dos fatos constitutivos do direito do autor e que o réu não tenha oposto provas capazes de gerar "dúvidas razoáveis". Segundo Marinoni, ${ }^{5}$ o conceito de "defesa inconsistente" já seria suficiente para abarcar todas as hipóteses do art. 311 do NCPC.

As tutelas provisórias conservam sua eficácia na pendência do processo, mas podem ser revogadas ou modificadas a qualquer tempo, uma vez que podem ser apresentados novos elementos processuais que podem alterar a convicção judicial. Quanto à eficácia temporal, a tutela somente funciona até o advento da tutela definitiva. Nesse sentido, a relação entre a tutela provisória e a definitiva é que só é possível antecipar aquilo que pode vir ao final; a tutela satisfativa antecipada guarda relação de identidade, total ou parcial, com a tutela satisfativa final, sendo que o provimento provisório é, então, um reflexo do definitivo.

Quanto à responsabilidade que nasce com o provimento da tutela provisória, a doutrina tende a entender que é caso de responsabilidade objetiva, no qual não é necessário demonstrar dolo ou culpa para que a outra parte, responsável pelo dano que foi impedido pela concessão da tutela provisória, arque com as consequências

documental suficiente dos fatos constitutivos do direito do autor, a que o réu não oponha prova capaz de gerar dúvida razoável."

5 MARINONI, Luiz Guilherme. Novo curso de processo civil. São Paulo: Revista dos Tribunais, 2015. v. 2. 
judiciais e patrimoniais da decisão. Nesse sentido, o equivalente na legislação é o art. 302 do NCPC. ${ }^{6}$

\section{A TUTELA DE URGÊNCIA NO PROCESSO TRIBUTÁRIO}

As ações tributárias normalmente são subdivididas a partir da legitimidade das partes para propor cada uma delas; dessa forma, analisam-se as ações propostas pelo fisco e pelo contribuinte. No primeiro caso, é comum que o fisco não se utilize de processos de natureza de conhecimento, uma vez que pode constituir unilateralmente seus títulos executivos. ${ }^{7}$ A autoridade fazendária busca constituir o crédito tributário por ela lançado e o faz por meio de processos de execução. Nessa seara, é possível que haja algum tipo de conduta dos contribuintes que gere uma ameaça ao adimplemento do crédito, e é essa a razão da existência de ações cautelares fiscais.

As cautelares fiscais possuem caráter cautelar por terem como objetivo instrumentalizar o processo de execução fiscal por meio de ritos procedimentais. Essa ação é alvo de diversas críticas na doutrina, tendo como principal questionamento a utilidade de tal ação, uma vez que a constituição do crédito tributário já garante ao poder público a possibilidade de ajuizar execução fiscal, com a penhora dos bens do devedor, para a defesa do adimplemento do crédito tributário.

Entretanto, o Superior Tribunal de Justiça (STJ) apresentou entendimento, no julgamento do Recurso Especial (REsp) n. 689.472/SE, de relatoria do Ministro Luiz Fux, em 5 de outubro de 2006, que "a medida cautelar fiscal, ensejadora de indisponibilidade do patrimônio do contribuinte, pode ser intentada mesmo antes da constituição do crédito tributário", ou seja, ainda na esfera administrativa pode ser proposta pela Fazenda a ação aqui em análise, funcionando como instrumento inibidor de eventuais recursos protelatórios. Os requisitos desse instrumento processual são os mesmos da tutela de urgência cautelar, sendo que, aqui, a fumaça do bom direito é caracterizada pela constituição do crédito tributário. ${ }^{8}$

6 "Art. 302. Independentemente da reparação por dano processual, a parte responde pelo prejuízo que a efetivação da tutela de urgência causar à parte adversa, se: I - a sentença the for desfavorável; II - obtida liminarmente a tutela em caráter antecedente, não fornecer os meios necessários para a citação do requerido no prazo de 5 (cinco) dias; III - ocorrer a cessação da eficácia da medida em qualquer hipótese legal; e IV - o juiz acolher a alegação de decadência ou prescrição da pretensão do autor."

7 SEGUNDO, Hugo de Brito Machado. Processo Tributário. 8. ed. São Paulo: Atlas, 2015.

8 SEGUNDO, Hugo de Brito Machado. Processo Tributário. 8. ed. São Paulo: Atlas, 2015. 
Por parte dos contribuintes, é possível a interposição da chamada medida liminar em mandado de segurança, instrumento pelo qual é possível a suspensão do ato impugnado, sempre tendo como base os requisitos da relevância do fundamento e a possibilidade de ineficácia da medida (art. $7^{\circ}$, inciso III, da Lei n. 12.016/2009). Tais requisitos são, em verdade, os mesmos das tutelas de urgência antecipadas - fumus boni juris e periculum in mora.

O primeiro requisito está relacionado a um conjunto probatório que convença o juiz, ao menos provisoriamente, de que o pedido formulado pelo autor possui amparo legal. Ainda, para a concessão de medida liminar, é necessário que a prestação de uma resposta jurisdicional concedida posteriormente não seja eficaz e cause danos ao autor em razão da perda ou deterioração do objeto, fundamento exposto no segundo requisito - perigo da demora.

Machado Segundo" apresenta importante distinção com relação aos "danos irreparáveis", consequências que devem ser tratadas, segundo o autor, não pelo instrumento das medidas liminares, mas pela impetração de mandado de segurança, sempre que direitos líquidos e certos estejam sendo violados. No caso das medidas liminares, o dano que pode ser causado está relacionado a uma ineficácia da resposta jurisdicional, emitindo uma sentença judicial sem objeto, a respeito de crédito tributário sobre dívida já prescrita, por exemplo. Atenta-se, por fim, à necessidade de reversibilidade das medidas liminares que, por sua essência, não representem um juízo satisfativo exauriente, limitando-se a guardar relação com a decisão final sem, contudo, antecipá-la.

Sob um aspecto mais favorável ao contribuinte, as medidas liminares ainda podem, segundo o art. 151 do Código Tributário Nacional (CTN), ser suficientes para suspender a exigibilidade do crédito tributário, afastando a necessidade de o devedor da Fazenda Pública depositar o montante integral supostamente devido. Esse instrumento processual possui capacidade de conceder os mesmos benefícios que o depósito judicial, garantindo maior segurança ao contribuinte durante as posteriores fases de discussão do crédito tributário.

Há, por fim, dois outros instrumentos de tutela provisória que o contribuinte pode utilizar no decorrer do processo tributário: a liminar em ação cautelar e a antecipação dos efeitos da tutela jurisdicional. O avanço do NCPC nessa seara veio com a necessidade de instrumentalização do processo como meio de proteção do direito material. A partir dessa concepção, práticas muito comuns que

9 SEGUNDO, Hugo de Brito Machado. Processo Tributário. 8. ed. São Paulo: Atlas, 2015. 
mitigavam direitos fundamentais dos contribuintes foram combatidas na medida em que se deixou de lado o formalismo extremo.

Caso típico de tal situação são justamente as tutelas de urgência do processo tributário, sendo comum que juízes negassem os pedidos realizados simplesmente por ter o contribuinte optado pela via processual equivocada, propondo uma ação cautelar nas situações em que era necessária a antecipação de tutela. $\mathrm{O}$ indeferimento de tutelas de urgência realmente necessárias com base no extremo formalismo já era considerado um ato violador do princípio da proporcionalidade e, com o NCPC, pode ser combatido.

Com relação ao uso das medidas liminares junto à compensação do crédito tributário, o autor Hugo de Brito Machado ${ }^{10}$ defende que é possível que se pleiteie a compensação a partir de decisões liminares; Isso porque não há uma extinção do crédito tributário, sendo possível que a Fazenda Pública o restabeleça e execute decisão judicial final que eventualmente a seja favorável, negando a existência do crédito ao contribuinte.

Tais entendimentos já foram acobertados pela jurisprudência do STJ no REsp n. 575.867/CE (Rel. Min. Teori Albino Zavascki, julgado em 5 de fevereiro de 2004) e no Agravo Regimental ao Agravo de Instrumento (ADA) n. 517.989/DF (Rel. Min. José Delgado, julgado em 16 de outubro de 2003), nos quais afirmaram que o objetivo das tutelas de urgência no processo tributário é a suspensão liminar da exigibilidade do crédito tributário que será, posteriormente, objeto de compensação. Nesse sentido, não são incompatíveis as medidas liminares e a compensação.

\section{A TUTELA DE EVIDÊNCIA NO PROCESSO TRIBUTÁRIO}

A aplicação da tutela de evidência em questões de direito tributário muito se assemelha às hipóteses de tutela de urgência, uma vez que se busca, por meio de ambas, a suspensão da exigibilidade do crédito tributário. Nesse sentido, vale ressaltar que o mais importante dispositivo que correlaciona a tutela de evidência e o processo tributário é o art. 311, inciso II, do NCPC. Segundo o dispositivo, o requisito para a concessão do mecanismo é o entendimento consolidado da tese discutida em recursos repetitivos e súmulas vinculantes. Em obediência à lógica dos precedentes, o NCPC buscou agilizar a concessão

10 MACHADO, Hugo de Brito. O direito de compensar e o artigo 170-A do CTN. In: ROCHA, Valdir de Oliveira (Coord.). Problemas de processo judicial tributário. São Paulo: Dialética, 2002. v. 5. 
da resposta jurisdicional nos casos em que já se mostra notório o entendimento a ser aplicado na hipótese concreta.

A tutela de evidência não requer que seja demonstrado o perigo do dano, mas exige a probabilidade do direito ainda mais latente que nas situações de tutela de urgência. Cabe ressaltar, entretanto, que não se pode confundir a concessão de tal tutela com o julgamento antecipado do mérito em razão do juízo não exauriente que a compõe. Nesse sentido, Wambier, Ribeiro, Conceição e Mello ${ }^{11}$ afirmam que "na tutela de evidência, diferentemente do julgamento antecipado, a decisão pauta-se em cognição sumária e, portanto, traduz uma decisão revogável e provisória".

É comum que se relacione o mandado de segurança, instituído pela Lei $\mathrm{n}$. 12.016/2009, com o instrumento ora analisado, uma vez que aquele é garantido ao interessado para defesa de direito líquido e certo e este pode ser utilizado sempre que estiver em evidência o direito do autor e a tese pleiteada - consolidada em sede de repetitivos e súmulas vinculantes. Nesse sentido, seria possível a concessão de tutela de evidência liminar em mandado de segurança tributário, como fica claro no exemplo trazido por André Vasconcelos Roque: ${ }^{12}$

Imaginemos que a ilicitude de determinado tributo tenha sido reconhecida em recurso especial repetitivo. Nas ações individuais subsequentes sobre a mesma matéria, bastaria ao autor, por exemplo, demonstrar documentalmente suas alegações e o enquadramento de seu caso na tese jurídica definida no recurso especial repetitivo para fazer jus à tutela de evidência que suspendesse a exigibilidade do tributo (art. 311, II), sem que fosse necessário demonstrar o periculum in mora.

Ao contribuinte, tal mecanismo se mostra bastante interessante principalmente se analisado em relação ao art. 151, inciso IV, do CTN, ${ }^{13}$ por assegurar a suspensão da exigibilidade do crédito tributário.

11 WAMBIER, Teresa; RIBEIRO, Leonardo Ferres da Silva; CONCEIÇÃO, Maria Lúcia Lins e; MELLO, Rogério Licastro Torres de. Primeiros comentários ao Novo CPC: artigo por artigo. São Paulo: Revista dos Tribunais, 2015, p. 68.

ROQUE, André Vasconcelos. Uma tutela nada evidente: a tutela da evidência recursal. São Paulo: JOTA, 21 dez. 2015. Disponivel em: <http://jota.uol.com.br/uma-tutela-nada-evidente-a-tutela-da-evidencia-recursal>. Acesso em: 23 set. 2016.

13 "Art. 151. Suspendem a exigibilidade do crédito tributário: I - moratória; II - o depósito do seu montante integral; III - as reclamações e os recursos, nos termos das leis reguladoras do processo tributário administrativo; e IV - a concessão de medida liminar em mandado de segurança." 
Assim, sempre que houver demonstração dos fatos por meio de provas cabais e a definição da tese jurídica em precedentes vinculantes, é interessante ao contribuinte interpor o mecanismo da tutela provisória de evidência.

\section{CONCLUSÃO}

Com a entrada em vigor do NCPC, amparando subsidiariamente o processo tributário, os contribuintes e a autoridade fiscal puderam lançar mão das tutelas provisórias para a obtenção de uma resposta jurisdicional do Estado mais célere e, em certo grau, satisfatória.

As inovações trazidas pelos dispositivos processuais prezaram pelo combate ao intenso formalismo que ameaçava a concessão dos direitos fundamentais, apresentando o processo mais como um instrumento para garantir o direito material que um empecilho burocrático, como era prática comum.

De fato, conforme a jurisprudência do Superior Tribunal de Justiça ${ }^{14}$, o deferimento da tutela provisória depende da demonstração de elementos que evidenciem a probabilidade do direito alegado e o perigo de dano ou o risco ao resultado útil do processo.

Para a concessão de tutela de urgência (art. 300 do CPC/2015), há se exigir a presença cumulada dos dois requisitos legais: a probabilidade do direito e o perigo de dano ou risco ao resultado útil do processo. Além disso, exige-se que não haja risco de irreversibilidade da medida. Vale destacar que o perigo de dano ou o risco ao resultado útil do processo, por sua vez, devem estar fundados em elementos objetivos, capazes de serem expostos de forma racional, e não em meras conjecturas de ordem subjetiva.

A concessão de tutelas provisórias dentro do processo tributário perpassa conflitos de princípios constitucionais inerentes ao devido processo legal, à efetiva prestação jurisdicional, ao contraditório, à ampla defesa e à segurança jurídica, mas

14 PROCESSUAL CIVIL. AGRAVO INTERNO NO PEDIDO DE TUTELA PROVISÓRIA. RECURSO ESPECIAL. PROBABILIDADE DO DIREITO ALEGADO. DEMONSTRAÇÃO. AUSÊNCIA. DECISÃO MANTIDA. 1. O deferimento de tutela provisória de urgência pressupõe a demonstração de elementos que evidenciem a probabilidade do direito alegado e o perigo de dano ou o risco ao resultado útil do processo. 2. No caso concreto, a agravante não logrou demonstrar a viabilidade das teses deduzidas no recurso especial. 3. Agravo interno a que se nega provimento. (Aglnt no TP 1.423/RJ, Rel. Ministro ANTONIO CARLOS FERREIRA, QUARTA TURMA, julgado em 26/06/2018, DJe 02/08/2018) 
é possível perceber que estas são instrumentos processuais bastante relevantes, principalmente para a proteção do crédito tributário e do contribuinte frente a cobranças abusivas.

Por parte do fisco, cautelares que assegurem a efetividade da execução fiscal e, por parte do contribuinte, liminares em mandados de segurança que suspendam a exigibilidade do crédito tributário são alguns exemplos que asseguram a paridade de armas necessária para uma correta composição das lides tributárias que diariamente chegam ao judiciário. 